\title{
Synthesis, Purification, and Mass Spectrometric Characterization of Stable Isotope-Labeled Amadori-Glycated Phospholipids
}

\author{
Xiaobo $\mathrm{He}^{\dagger}$ and Qibin Zhang*, ${ }^{*}, \ddagger$ (1) \\ ${ }^{\dagger}$ Center for Translational Biomedical Research, University of North Carolina at Greensboro, North Carolina Research Campus, \\ Kannapolis, North Carolina 28081, United States \\ ${ }^{\ddagger}$ Department of Chemistry \& Biochemistry, University of North Carolina at Greensboro, Greensboro, North Carolina 27412, United \\ States
}

\section{Supporting Information}

ABSTRACT: Nonenzymatic glycation of lipids plays an important role in several physiological and pathological processes, such as normal aging and complications of diabetes mellitus. To develop liquid chromatography coupled with mass spectrometric (LC-MS) methods for accurate analysis of Amadori compound-glycated lipids from biological samples, it is essential to obtain isotope-labeled Amadori-lipid standards. Herein, we report optimized methods for the preparation of six stable isotope-labeled Amadori-glycated lipid standards covering four types of lipids, including $\left[{ }^{13} \mathrm{C}_{6}\right]$ Amadori-phosphatidyl ethanolamine (PE), -phosphatidyl serine (PS), -LysoPE, and -LysoPS. Optimal conditions for the synthesis and purification of these four types of Amadori-glycated lipids were detailed in this study. LC-MS and LC-UV analyses showed that destination products were highly purified ( $>95 \%)$. Accurate mass and MS/MS fragmentation in both positive- and negative-ion modes further validated the identification of these six synthetic $\left[{ }^{13} \mathrm{C}_{6}\right]$ Amadori-glycated lipid standards. Successful preparation of these highly purified isotope-labeled standards makes it possible to develop targeted LC-MS/MS methods for accurate analysis of Amadori-glycated phospholipids from biological samples.
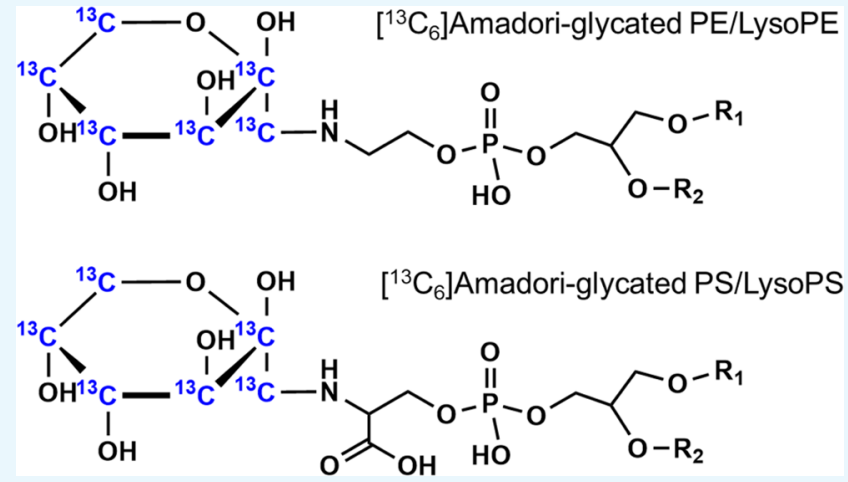

\section{INTRODUCTION}

Nonenzymatic glycation, generally known as the Maillard reaction, is triggered by reaction of amino group in biomolecules and carbonyl function of reducing sugars (glucose, fructose, ribose, etc.) to form an unstable Schiff base, followed by the Amadori rearrangement reaction to form a more stable Amadori product. ${ }^{1}$ Furthermore, Amadori compounds can undergo complex reactions to form advanced glycation end products (AGEs). ${ }^{1}$ The Amadorimodified compounds and AGEs are implicated in the pathogenesis of age-related diseases and complications of mellitus. ${ }^{1-4}$

The Maillard reaction of proteins and peptides has attracted the most attention in glycation and advanced glycation studies. ${ }^{1}$ However, aminophospholipids are also important targets of nonenzymatic glycation. ${ }^{3}$ For example, the nonenzymatic glycation of membrane lipids can cause peroxidation of proteins and membrane lipids, inactivation of receptors, and other membrane dysfunctions, which are involved in various physiological and pathological processes, such as aging, diabetes, atherogenesis. ${ }^{4-10}$ In vitro, Amadori products were reported with the ability to generate reactive oxygen species, which can further lead to lipid peroxidation involved in many physiological and pathological processes. $^{11}$

To better understand the roles of Amadori-glycated lipids in physiological and pathological processes, it is essential to develop analytical methods for a comprehensive profiling of Amadoriglycated lipid species in biological samples. To date, reported methods using liquid chromatography coupled with mass spectrometric (LC-MS) technique have focused on Amadoriphosphatidyl ethanolamine (PE) with a few identified molecular species. ${ }^{12-14}$ For lipidomic level investigation on Amadoriglycated lipids, LC-MS/MS methods with high sensitivity should be developed for measuring various types of Amadori lipids. To this end, it is necessary to obtain stable isotope-labeled Amadori-glycated lipid standards with high purity.

Several preparation methods for Amadori-PE were already reported. However, these methods are not well suited for preparing stable-isotope-labeled standards, in that either a complex process of six steps is used ${ }^{15,16}$ or synthesis is carried out in methanol $(\mathrm{MeOH})$ phosphate buffer $(\mathrm{PB})$ medium, which requires a long reaction time ( 15 days) and a high amount of glucose $(500 \mathrm{mM}),{ }^{11,17}$ the latter is prohibitive for isotopelabeled Amadori compound synthesis due to the high cost of $\left[{ }^{13} \mathrm{C}_{6}\right]$ glucose. A revised method using $\mathrm{MeOH}$ medium was also reported for the synthesis of Amadori-PE, ${ }^{17-19}$ which

Received: August 3, 2018

Accepted: November 6, 2018

Published: November 19, 2018 
requires a shorter reaction time $(12 \mathrm{~h})$ and less amount of glucose $(100 \mathrm{mM})$. In spite of the methods mentioned above, no data are available about how yields change under various conditions, such as temperature, reaction duration, the ratio of reactants, and reaction medium. Considering the high cost of $\left[{ }^{13} \mathrm{C}_{6}\right]$ glucose, optimal conditions are required for the preparation of $\left[{ }^{13} \mathrm{C}_{6}\right]$ Amadori-PE standards. In addition, to our knowledge, preparation of Amadori-phosphatidyl serine (PS), -LysoPE, and -LysoPS has not been reported yet. Herein, we present optimized methods for the preparation of $\left[{ }^{13} \mathrm{C}_{6}\right]$ Amadori-PE, -PS, -LysoPE, and -LysoPS with high purity. The identification of these synthetic $\left[{ }^{13} \mathrm{C}_{6}\right]$ Amadori-lipid standards was performed by LC-MS/MS analysis in both positive- and negative-ion modes, and distinctive ions were identified for $\left[{ }^{13} \mathrm{C}_{6}\right]$ Amadori-modified lipids.

\section{MATERIALS AND METHODS}

2.1. Chemical and Solvent. 1-Palmitoyl-2-oleoylsn-glycero-3-phosphoethanolamine (PE(16:0/18:1(9Z))), 1, 2-dipentadecanoyl-sn-glycero-3-phosphoethanolamine (PE(15:0/15:0)), 1-tridecanoyl-sn-glycero-3-phosphoethanolamine (LysoPE(13:0)), 1-palmitoyl-2-oleoyl-sn-glycero-3-phospho-Lserine (PS(16:0/18:1(9Z))), 1,2-diheptadecanoyl-sn-glycero-3phospho-L-serine (PS(17:0/17:0)), and 1-tridecanoyl-sn-glycero-3-phospho-L-serine (LysoPS(13:0)) were purchased from Avanti Polar Lipids (Alabaster, AL). $\left[\mathrm{U}^{13} \mathrm{C}_{6}\right]$-D-glucose (99\%) was purchased from Cambridge Isotope Laboratories (Tewksbury, MA). Butylated hydroxytoluene 2,6-di-tert-butyl-p-cresol (BHT) and all solvents, including $\mathrm{MeOH}$, acetonitrile (ACN), isopropanol (IPA), chloroform $\left(\mathrm{CHCl}_{3}\right)$, and water $\left(\mathrm{H}_{2} \mathrm{O}\right)$, of LC-MS grade and high performance liquid chromatography (HPLC) grade were purchased from Fisher Scientific (Pittsburgh, PA).

2.2. Optimization of Synthetic Conditions. On the basis of the work of Miyazawa and co-workers, ${ }^{11,17,18}$ we carried out a series of incubations to optimize conditions for the synthesis of $\left[{ }^{13} \mathrm{C}_{6}\right]$ Amadori-glycated lipids.

To find which medium (MeOH or $\mathrm{MeOH}-\mathrm{PB})$ is better for the synthesis of $\left[{ }^{13} \mathrm{C}_{6}\right]$ Amadori-lipids and whether BHT could increase the reaction yield, three incubations were performed as follows: (A) $7 \mu \mathrm{mol} \mathrm{PE}(16: 0 / 18: 1(9 \mathrm{Z}))$ was mixed with $537 \mu \mathrm{mol}\left[{ }^{13} \mathrm{C}_{6}\right] \mathrm{D}$-glucose in $5 \mathrm{~mL}$ of $\mathrm{MeOH}-0.1 \mathrm{M} \mathrm{PB}(1: 2$, v/v, pH 8) at $37^{\circ} \mathrm{C}$; (B) $7 \mu \mathrm{mol} \mathrm{PE}(16: 0 / 18: 1(9 \mathrm{Z}))$ was mixed with $107 \mu \mathrm{mol}\left[{ }^{13} \mathrm{C}_{6}\right] \mathrm{D}$-glucose in $1 \mathrm{~mL}$ of $\mathrm{MeOH}$ at $37^{\circ} \mathrm{C}$ with and without $0.3 \mathrm{mg}$ of $\mathrm{BHT}$.

To further optimize the reaction temperature and time, $7 \mu \mathrm{mol}$ $\mathrm{PE}(16: 0 / 18: 1(9 \mathrm{Z}))$ was mixed with $107 \mu \mathrm{mol}\left[{ }^{13} \mathrm{C}_{6}\right] \mathrm{D}$-glucose in $1 \mathrm{~mL}$ of $\mathrm{MeOH}$ and the mixture was stirred at $600 \mathrm{rpm}$ in a Thermomix mixer (Eppendorf, Germany) at 37, 50, or $60{ }^{\circ} \mathrm{C}$. At different time intervals (0-4 days), aliquots of reaction mixtures were collected for analysis. Incubations of $\left[{ }^{13} \mathrm{C}_{6}\right] \mathrm{D}$-glucose with LysoPE(13:0), PS(16:0/18:1(9Z)), and LysoPS(13:0) were carried out similarly.

Optimization of reactant ratio was performed as follows: $7 \mu \mathrm{mol} \mathrm{PE}(16: 0 / 18: 1(9 \mathrm{Z}))$ was incubated in $1 \mathrm{~mL}$ of $\mathrm{MeOH}$ at $60{ }^{\circ} \mathrm{C}$ with $54,107,161$ and $215 \mu \mathrm{mol}$ of $\left[{ }^{13} \mathrm{C}_{6}\right] \mathrm{D}$-glucose.

2.3. Purification of Amadori-Glycated Lipids. 2.3.1. Lipid Extraction. For $\left[{ }^{13} \mathrm{C}_{6}\right]$ Amadori-PE/PS species, the Folch method was performed to remove $\left[{ }^{13} \mathrm{C}_{6}\right]$ glucose and other water-soluble byproducts. After incubation, the reaction mixture in $1 \mathrm{~mL}$ of $\mathrm{MeOH}$ was mixed with $2 \mathrm{~mL}$ of $\mathrm{CHCl}_{3}$ and $0.6 \mathrm{~mL}$ of $\mathrm{H}_{2} \mathrm{O}$. The mixture was vortexed for $20 \mathrm{~s}$ and then centrifuged at $3000 \mathrm{rpm}$ for $15 \mathrm{~min}$. The bottom layer was transferred out by a glass pipette and then dried with nitrogen.

2.3.2. $C_{18}$ Solid-Phase Extraction (SPE). Because of the high hydrophilicity of $\left[{ }^{13} \mathrm{C}_{6}\right]$ Amadori-LysoPE/LysoPS species, the Folch method cannot be used for liquid-liquid extraction. Instead, $\mathrm{C}_{18}$ SPE was employed to separate synthetic products from $\left[{ }^{13} \mathrm{C}_{6}\right]$ glucose or other water-soluble materials. In brief, incubation mixture was reconstituted in $10 \% \mathrm{MeOH}$ and then loaded onto an ISOLUTE $\mathrm{C}_{18}$ cartridge $(500 \mathrm{mg}$, Biotage, Sweden) conditioned with the same solvent. After rinsing with an additional $5 \mathrm{~mL}$ of $10 \% \mathrm{MeOH}$, Amadori lipids were eluted out with $10 \mathrm{~mL}$ of $\mathrm{MeOH}$.

2.3.3. Phenylboronic Acid (PBA) SPE. Diol-containing Amadori-glycated lipids can bind to immobilized PBA, which enables isolation of Amadori-glycated lipids from their corresponding lipids. Bond Elut PBA cartridges $(500 \mathrm{mg})$ purchased from Agilent (Palo Alto, CA) were adopted to perform SPE for cleanup. Briefly, PBA cartridges were wetted with $5 \mathrm{~mL}$ of $\mathrm{MeOH}$ and then conditioned with $3 \mathrm{~mL}$ of $150 \mathrm{mM}$ ammonium formate (AF, pH 10), followed by $5 \mathrm{~mL}$ of $20 \% \mathrm{MeOH}$ containing $100 \mathrm{mM} \mathrm{AF}$ ( $\mathrm{pH} \mathrm{8}$ ) (loading solvent). The dried resultant lipid extracts were redissolved in $\mathrm{MeOH}$ and diluted 10 times with loading solvent before loading onto equilibrated PBA cartridges. The cartridges were rinsed with $5 \mathrm{~mL}$ of $\mathrm{MeOH}$ containing $0.1 \%(\mathrm{v} / \mathrm{v})$ ammonium hydroxide, then $\left[{ }^{13} \mathrm{C}_{6}\right]$ Amadori-lipids were recovered by elution with $5 \mathrm{~mL}$ of $90 \% \mathrm{MeOH}$ containing $1 \%$ formic acid. The elution effluent was nitrogen-dried and subjected to the following HPLC separation.

2.3.4. HPLC-UV Separation. Semipreparative separation was performed on a Shimadzu 20A HPLC equipped with LC-8A pumps. The samples were loaded onto a Kromasil $\mathrm{C}_{18}$ column $(250 \times 10 \mathrm{~mm}, 10 \mu \mathrm{m}$, AkzoNobel, Bohus, Sweden) using four isocratic mobile phases at a flow rate of $3 \mathrm{~mL} / \mathrm{min}$ for different $\left[{ }^{13} \mathrm{C}_{6}\right]$ Amadori-lipid species: $\left[{ }^{13} \mathrm{C}_{6}\right]$ Amadori-PE: $100 \% \mathrm{MeOH}$ containing $5 \mathrm{mM}$ AF; $\left[{ }^{13} \mathrm{C}_{6}\right]$ Amadori-PS: $100 \% \mathrm{MeOH}$ containing $5 \mathrm{mM} \mathrm{AF}$ and $0.1 \%$ phosphoric acid; $\left[{ }^{13} \mathrm{C}_{6}\right]$ AmadoriLysoPE: $80 \% \mathrm{MeOH}$ containing $5 \mathrm{mM} \mathrm{AF}$; and $\left[{ }^{13} \mathrm{C}_{6}\right]$ Amadori-LysoPS: $75 \% \mathrm{MeOH}$ containing $5 \mathrm{mM}$ AF and $0.1 \%$ phosphoric acid. The effluent was monitored for UV absorbance at $220 \mathrm{~nm}$, and the injection volume was set at $500 \mu \mathrm{L}$.

2.4. LC-MS Analysis of $\left[{ }^{13} C_{6}\right]$ Amadori-Lipids. A Vanquish UHPLC system coupled to a TSQ Quantiva triple quadrupole mass spectrometer (Thermo Fisher Scientific) was primarily used for the analysis of $\left[{ }^{13} \mathrm{C}_{6}\right]$ Amadori-lipids. A core-shell Accucore C30 column (Thermo Fisher Scientific) was used with a column oven temperature of $40{ }^{\circ} \mathrm{C}$ and a flow rate of $350 \mu \mathrm{L} / \mathrm{min}$. Two elution gradients were employed for the analysis of $\left[{ }^{13} \mathrm{C}_{6}\right]$ Amadori-PE/PS and $\left[{ }^{13} \mathrm{C}_{6}\right]$ Amadori-LysoPE/LysoPS, respectively, as follows:

Gradient 1: Identical to the method previously published by our laboratory for global lipidomics analysis, ${ }^{20}$ the mobile phase was composed of solvent $\mathrm{A}\left(\mathrm{ACN} / \mathrm{H}_{2} \mathrm{O}, 60: 40, \mathrm{v} / \mathrm{v}\right)$ and solvent $\mathrm{B}$ (IPA/ACN, 90:10, v/v), both containing $10 \mathrm{mM}$ AF and $0.1 \%$ formic acid. The gradient was as follows: -3 to $0 \mathrm{~min}, 30 \% \mathrm{~B}$ for column equilibration; $0-5 \mathrm{~min}, 30-43 \% \mathrm{~B}$; 5-5.1 $\mathrm{min}, 43-$ $50 \%$ B; 5.1-14 min, 50-70\% B; 14.1-21 min, 70-99\% B; 21-24 min, 99\% B; 24-24.1 min, 99-30\% B; 24.1-28 min, $30 \% \mathrm{~B}$ for column reequilibration. The total analysis time including column reequilibration was $31 \mathrm{~min}$.

Gradient 2: The mobile phase was composed of solvent A $\left(\mathrm{H}_{2} \mathrm{O}\right)$ and solvent $\mathrm{B}(\mathrm{MeOH})$, both containing $5 \mathrm{mM} \mathrm{AF}$ and $0.1 \%$ formic acid. The gradient was as follows: -3 to $0 \mathrm{~min}$, 


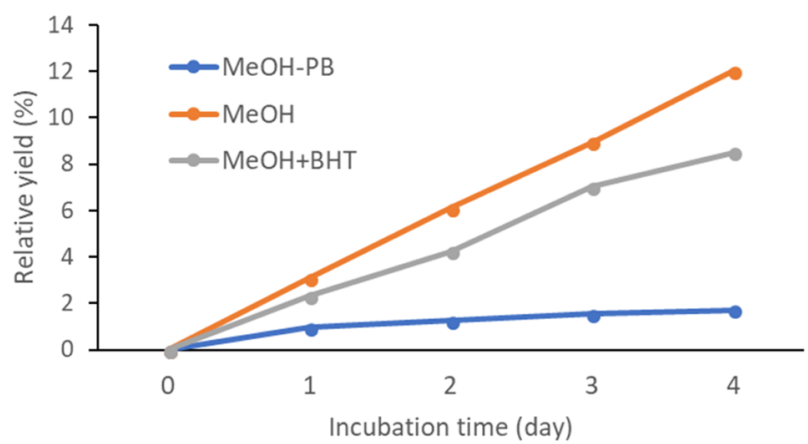

Figure 1. Reaction yields of $\left[{ }^{13} \mathrm{C}_{6}\right] \mathrm{Amadori}-\mathrm{PE}(16: 0 / 18: 1(9 \mathrm{Z}))$ in the medium of $\mathrm{MeOH}-\mathrm{PB}, \mathrm{MeOH}$, or $\mathrm{MeOH}$ in the presence of BHT.

isocratic elution with $60 \% \mathrm{~B}$ for the equilibration of the column; 0-3 min, 60\% B; 3-13 min, 60-99\% B; $13-15 \mathrm{~min}$, $99 \% \mathrm{~B} ; 15-15.1 \mathrm{~min}, 99-60 \% \mathrm{~B} ; 15.1-19 \mathrm{~min}, 60 \% \mathrm{~B}$ for column reequilibration. The total analysis time including column reequilibration was $22 \mathrm{~min}$.

The TSQ Quantiva mass spectrometer was equipped with a heated electrospray ionization source, with positive- and negative-ion spray voltages set at 3500 and $3000 \mathrm{~V}$, respectively. For both ionization modes, nitrogen was used as the sheath, auxiliary, and sweep gases at flow rates of 20, 7, and 1 (arbitrary units), respectively. Vaporizer and ion-transfer tube temperatures were 400 and $350{ }^{\circ} \mathrm{C}$, respectively. For MS analysis in full-scan mode, the scan range, scan rate, and resolution were $\mathrm{m} / z$ 200-1000, $1000 \mathrm{amu} / \mathrm{s}$, and 0.7 (full width at half maximum), respectively. For MS/MS analysis in product ion scan mode, the argon collision gas pressure was $1.5 \mathrm{mTorr}$. The optimized collision energy was $20 \mathrm{eV}$ for $\left[{ }^{13} \mathrm{C}_{6}\right]$ Amadori-PE and
$16 \mathrm{eV}$ for $\left[{ }^{13} \mathrm{C}_{6}\right]$ Amadori-PS/LysoPE/LysoPS in positive-ion mode, whereas it is $27 \mathrm{eV}$ for $\left[{ }^{13} \mathrm{C}_{6}\right]$ Amadori-PE/PS and $22 \mathrm{eV}$ for $\left[{ }^{13} \mathrm{C}_{6}\right]$ Amadori-LysoPE/LysoPS in negative-ion mode.

For high-resolution mass analysis, a Q Exactive HF hybrid quadrupole-Orbitrap mass spectrometer (Thermo Fisher Scientific) was coupled to a Vanquish UPLC, as described above for TSQ Quantiva. Mass ranges for full-scan MS and mass resolution settings were $m / z \quad 100-1000$ and 120000 , respectively.

\section{RESULTS AND DISCUSSION}

3.1. Optimization of Synthetic Conditions. To determine the relative yield of $\left[{ }^{13} \mathrm{C}_{6}\right]$ Amadori-glycated lipids, LC-MS analysis in full-scan mode was performed to quantify $\left[{ }^{13} \mathrm{C}_{6}\right]$ Amadori-lipids synthesized under different conditions. An assumption was made that Amadori-glycated lipids have similar ionization efficiency to their corresponding unmodified lipids, so chromatographic peak areas were used to estimate the relative reaction yield.

$$
\begin{aligned}
\text { relative yield }(\%)= & \text { peak area of Amadori-lipid yielded } \\
& / \text { peak area of initial lipid reactant } \\
& \times 100 \%
\end{aligned}
$$

Reactions of $\mathrm{PE}(16: 0 / 18: 1(9 \mathrm{Z}))$ with $\left[{ }^{13} \mathrm{C}_{6}\right] \mathrm{D}$-glucose in $\mathrm{MeOH}-\mathrm{PB}, \mathrm{MeOH}$, and $\mathrm{MeOH}$ with addition of $\mathrm{BHT}$ were carried out at $37{ }^{\circ} \mathrm{C}$ in parallel. After incubation for $0,1,2,3$, and 4 days, aliquots of reaction mixtures were dried and then subjected to Folch extraction. $\mathrm{CHCl}_{3}$ layer was transferred out, dried, reconstituted in $\mathrm{MeOH}$, and then subjected to LC-MS analysis.

As shown in Figure 1, reaction yield in complete $\mathrm{MeOH}$ medium was $3.2,4.9,5.8$, and 7.0 times higher than those in $\mathrm{MeOH}-\mathrm{PB}$ after incubation for 1, 2, 3, and 4 days, respectively.
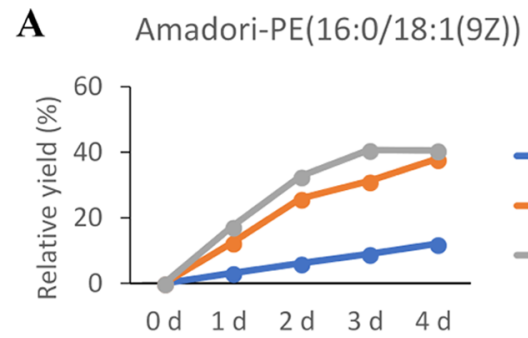

C

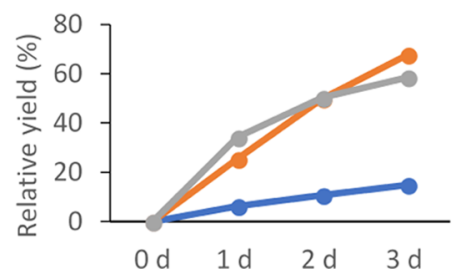

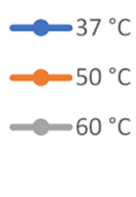

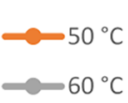

B

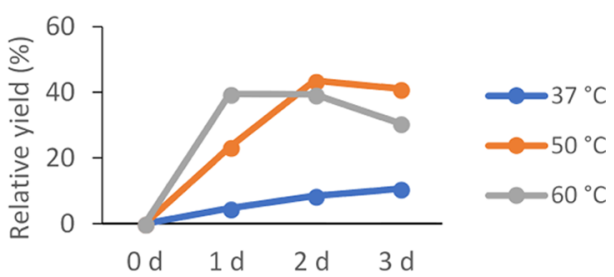

D

Amadori-LysoPS(13:0)

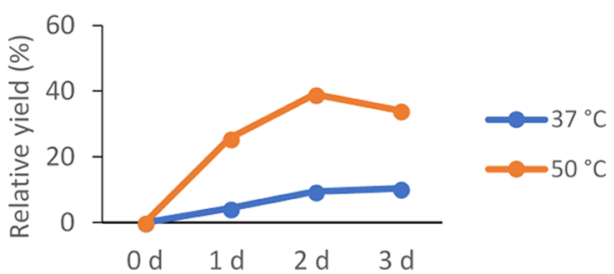

Figure 2. Effect of temperature and time on reaction yields of $(\mathrm{A})\left[{ }^{13} \mathrm{C}_{6}\right]$ Amadori-PE(16:0/18:1(9Z)), (B) $\left[{ }^{13} \mathrm{C}_{6}\right] \mathrm{Amadori}-\mathrm{PS}(16: 0 / 18: 1(9 \mathrm{Z}))$,

\begin{tabular}{|c|c|c|c|c|c|}
\hline & medium & temperature $\left({ }^{\circ} \mathrm{C}\right)$ & incubation duration (days) & concentration of lipids $(\mu \mathrm{mol} / \mathrm{mL})$ & $\begin{array}{l}\text { concentration of }\left[{ }^{13} \mathrm{C}_{6}\right] \mathrm{D} \\
\text {-glucose }(\mu \mathrm{mol} / \mathrm{mL})\end{array}$ \\
\hline$\left[{ }^{13} \mathrm{C}_{6}\right]$ Amadori-PE & $\mathrm{MeOH}$ & 60 & 3 & 7 & 161 \\
\hline$\left[{ }^{13} \mathrm{C}_{6}\right]$ Amadori-PS & $\mathrm{MeOH}$ & 50 & 2 & 7 & 161 \\
\hline$\left[{ }^{13} \mathrm{C}_{6}\right]$ Amadori-LysoPE & $\mathrm{MeOH}$ & 50 & 3 & 12 & 215 \\
\hline$\left[{ }^{13} \mathrm{C}_{6}\right]$ Amadori-LysoPS & $\mathrm{MeOH}$ & 50 & 2 & 10 & 215 \\
\hline
\end{tabular}
(C) $\left[{ }^{13} \mathrm{C}_{6}\right]$ Amadori-LysoPE(13:0/0:0), and (D) $\left[{ }^{13} \mathrm{C}_{6}\right]$ Amadori-LysoPS(13:0/0:0).

Table 1. Optimized Synthetic Conditions for $\left[{ }^{13} \mathrm{C}_{6}\right]$ Amadori-Lipids 


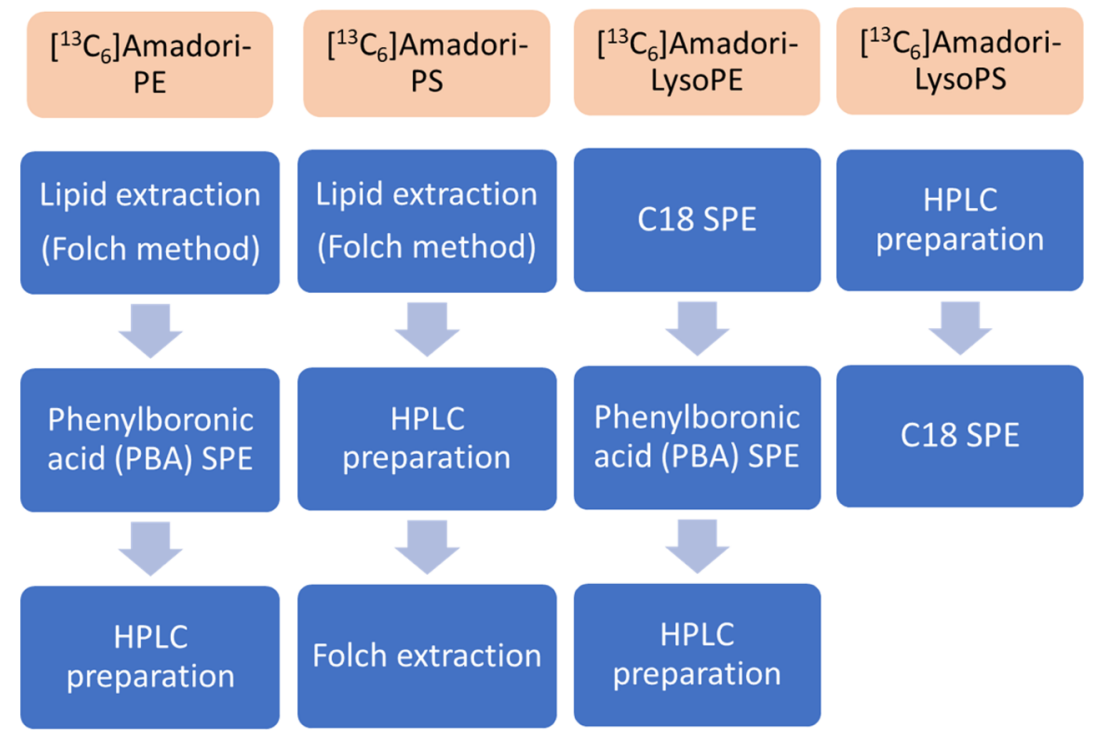

Figure 3. Outline of protocols for purification of $\left[{ }^{13} \mathrm{C}_{6}\right]$ Amadori-lipids.

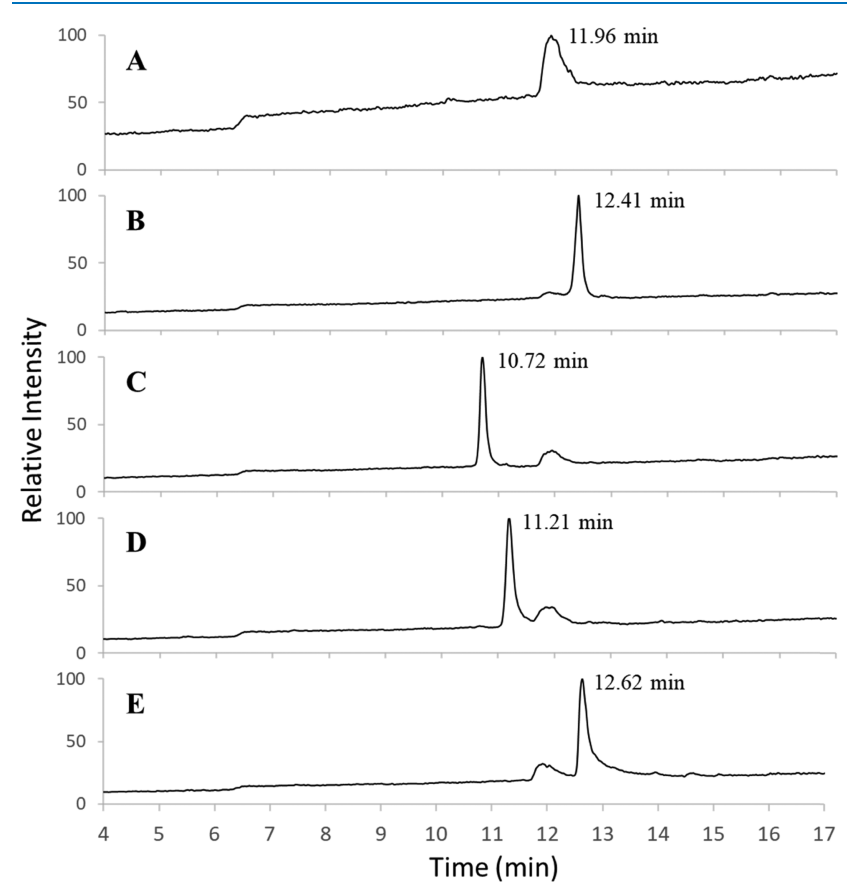

Figure 4. LC-MS full-scan chromatograms of (A) blank control, and purified (B) $\left[{ }^{13} \mathrm{C}_{6}\right]$ Amadori-PE $(16: 0 / 18: 1(9 \mathrm{Z}))$, (C) $\left[{ }^{13} \mathrm{C}_{6}\right]$ Amadori$\operatorname{PE}(15: 0 / 15: 0)$, (D) $\left[{ }^{13} \mathrm{C}_{6}\right]$ Amadori-PS $(16: 0 / 18: 1(9 \mathrm{Z}))$, and (E) $\left[{ }^{13} \mathrm{C}_{6}\right]$ Amadori-PS $(17: 0 / 17: 0)$. The mass range for full-scan analysis was $m / z 200-1000$. The peak at $11.96 \mathrm{~min}$ appearing in all plots of this figure was from background.

On the other hand, yields in $\mathrm{MeOH}$ were 1.3, 1.4, 1.3, and 1.4 times higher than those in $\mathrm{MeOH}+\mathrm{BHT}$ after 1, 2, 3, and 4 days, respectively. BHT, a synthetic antioxidant that can effectively inhibit the browning reaction and lipid peroxidation, ${ }^{17,21,22}$ was expected to prevent the formation of secondary byproducts and thus increase the recovery of destination product; however, our results showed that addition of BHT did not help the production of $\left[{ }^{13} \mathrm{C}_{6}\right]$ Amadori-PE.

In terms of effects of reaction temperature and time, as shown in Figure 2, yields peaked at $60{ }^{\circ} \mathrm{C}$ and 3 days for $\left[{ }^{13} \mathrm{C}_{6}\right]$ Amadori-PE, $50{ }^{\circ} \mathrm{C}$ and 3 days for $\left[{ }^{13} \mathrm{C}_{6}\right]$ AmadoriLysoPE, and $50{ }^{\circ} \mathrm{C}$ and 2 days for $\left[{ }^{13} \mathrm{C}_{6}\right]$ Amadori-PS/LysoPS.

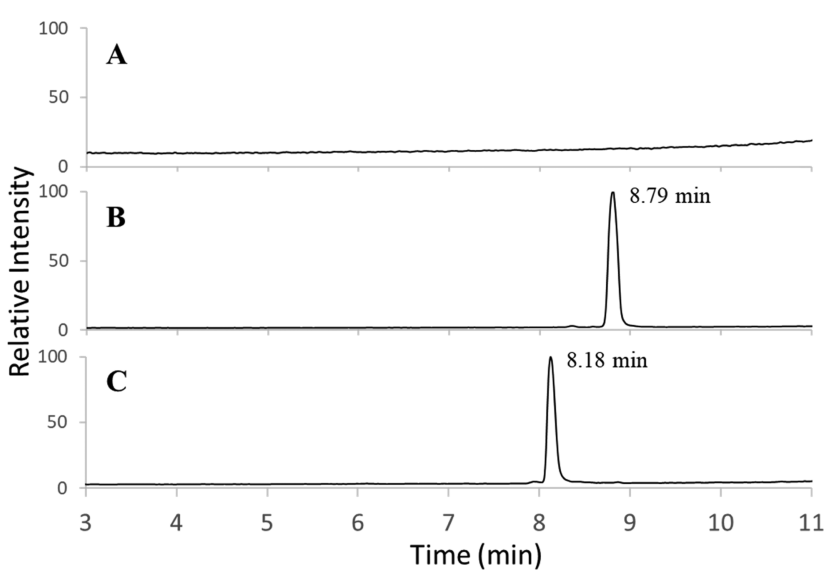

Figure 5. LC-MS full-scan chromatograms of (A) blank control, and purified (B) $\left[{ }^{13} \mathrm{C}_{6}\right]$ Amadori-LysoPE $(13: 0 / 0: 0)$ and (C) $\left[{ }^{13} \mathrm{C}_{6}\right]$ Amadori-LysoPS(13:0/0:0). The mass range for full-scan analysis was $m / z 200-1000$.

To optimize the ratio of reactants, incubations of $7 \mu \mathrm{mol}$ $\mathrm{PE}(16: 0 / 18: 1(9 \mathrm{Z}))$ in $1 \mathrm{~mL}$ of $\mathrm{MeOH}$ at $60^{\circ} \mathrm{C}$ with 54, 107, 161 , and $215 \mu \mathrm{mol}\left[{ }^{13} \mathrm{C}_{6}\right] \mathrm{D}$-glucose were carried out in parallel, with the corresponding molar ratios of $\left[{ }^{13} \mathrm{C}_{6}\right]$ glucose over $\mathrm{PE}(16: 0 / 18: 1(9 \mathrm{Z}))$ being 7.7, 15.4, 23.1, and 30.9. After 3 days of incubation, the resulting yields were 19.9, 40.6, 49.9, and $53.0 \%$ for the molar ratios of $7.7,15.4,23.1$, and 30.9 , respectively. This result showed that yields increased with increasing molar ratio of $\left[{ }^{13} \mathrm{C}_{6}\right]$ glucose over PE. However, the increase of yield was not significant when the molar ratio increased from 23.1 to 30.9. As such, molar ratios of $\left[{ }^{13} \mathrm{C}_{6}\right] \mathrm{D}$-glucose over lipids were optimized to about 23 for the synthesis of all Amadoriglycated lipids. The optimized synthetic conditions for $\left[{ }^{13} \mathrm{C}_{6}\right]$ Amadori-PE/PS/LysoPE/LysoPS are listed in Table 1.

3.2. Purification and Identification of $\left[{ }^{13} C_{6}\right]$ AmadoriGlycated Lipids. Purification methods differed between $\left[{ }^{13} \mathrm{C}_{6}\right]$ Amadori-PE/PS, $\left[{ }^{13} \mathrm{C}_{6}\right]$ Amadori-LysoPE, and $\left[{ }^{13} \mathrm{C}_{6}\right]$ Amadori-LysoPS because of their different chemical properties. Figure 3 shows the flowchart for purification of $\left[{ }^{13} \mathrm{C}_{6}\right]$ AmadoriPE, -PS, -LysoPE, and -LysoPS, as synthesized in Section 3.1.

In terms of $\left[{ }^{13} \mathrm{C}_{6}\right]$ Amadori-PE/PS species, we first removed $\left[{ }^{13} \mathrm{C}_{6}\right] \mathrm{D}$-glucose from the incubation mixture by liquid-liquid 

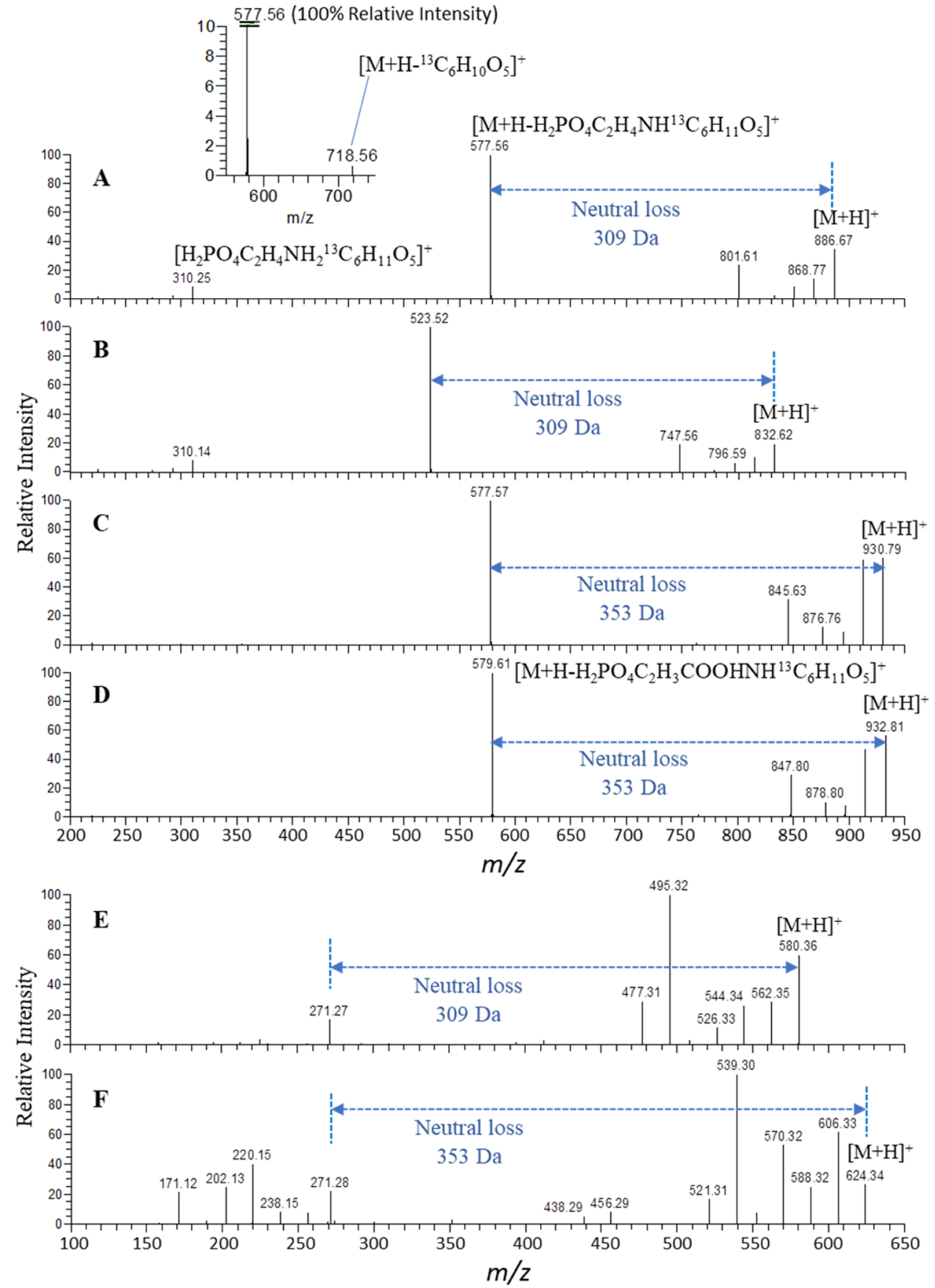

Figure 6. MS/MS spectra for molecular ion peaks of (A) $\left[{ }^{13} \mathrm{C}_{6}\right]$ Amadori-PE(16:0/18:1(9Z)), (B) $\left[{ }^{13} \mathrm{C}_{6}\right] \mathrm{Amadori}-\mathrm{PE}(15: 0 / 15: 0)$, (C) $\left[{ }^{13} \mathrm{C}_{6}\right]$ Amadori-PS (16:0/18:1(9Z)), (D) $\left[{ }^{13} \mathrm{C}_{6}\right]$ Amadori-PS(17:0/17:0), (E) $\left[{ }^{13} \mathrm{C}_{6}\right]$ Amadori-LysoPE $(13: 0 / 0: 0)$, and $(\mathrm{F})\left[{ }^{13} \mathrm{C}_{6}\right]$ AmadoriLysoPS(13:0/0:0) in positive-ion mode. The inset shows the magnified $m / z$ 550-750 region of (A).

extraction, for which the Folch method was employed. Diolcontaining glucose has the ability to bind to immobilized PBA, ${ }^{23,24}$ which will likely affect the binding between PBA and $\left[{ }^{13} \mathrm{C}_{6}\right]$ Amadori-lipids. After lipid extraction, PBA SPE was performed to separate $\left[{ }^{13} \mathrm{C}_{6}\right]$ Amadori-PEs from their corresponding substrates, according to the reversible covalent interaction between PBA and diol-containing $\left[{ }^{13} \mathrm{C}_{6}\right]$ Amadori-PEs. $\left[{ }^{13} \mathrm{C}_{6}\right]$ Amadori-PEs were finally purified by semipreparative HPLC. As for $\left[{ }^{13} \mathrm{C}_{6}\right]$ Amadori-PS species, however, PBA SPE was not applicable because $\left[{ }^{13} \mathrm{C}_{6}\right]$ Amadori-PSs could not be retained well on PBA SPE column. A similar poor retention was also observed for $\left[{ }^{13} \mathrm{C}_{6}\right]$ Amadori-LysoPS. The possible reason is that $\left[{ }^{13} \mathrm{C}_{6}\right]$ Amadori-PS/LysoPS carries negative charge under alkaline conditions, which results in electrostatic repulsion from immobilized boronate. ${ }^{25}$ In contrast to $\left[{ }^{13} \mathrm{C}_{6}\right]$ Amadori-PE, the separation performance of $\left[{ }^{13} \mathrm{C}_{6}\right]$ Amadori-PS on $\mathrm{C}_{18}$ column was improved largely by adding acid to mobile phase. Consequently, $\left[{ }^{13} \mathrm{C}_{6}\right]$ Amadori-PSs were purified on a semipreparative $\mathrm{C}_{18}$ column using isocratic elution with $100 \% \mathrm{MeOH}$ containing $5 \mathrm{mM}$ $\mathrm{AF}$ and $0.1 \%$ phosphoric acid, then one more Folch extraction was employed to remove phosphoric acid in eluent from purified compounds.

LC-MS full-scan chromatograms (Figure 4) showed that $\left[{ }^{13} \mathrm{C}_{6}\right]$ Amadori-PE(16:0/18:1(9Z)), $-\mathrm{PE}(15: 0 / 15: 0)$, 


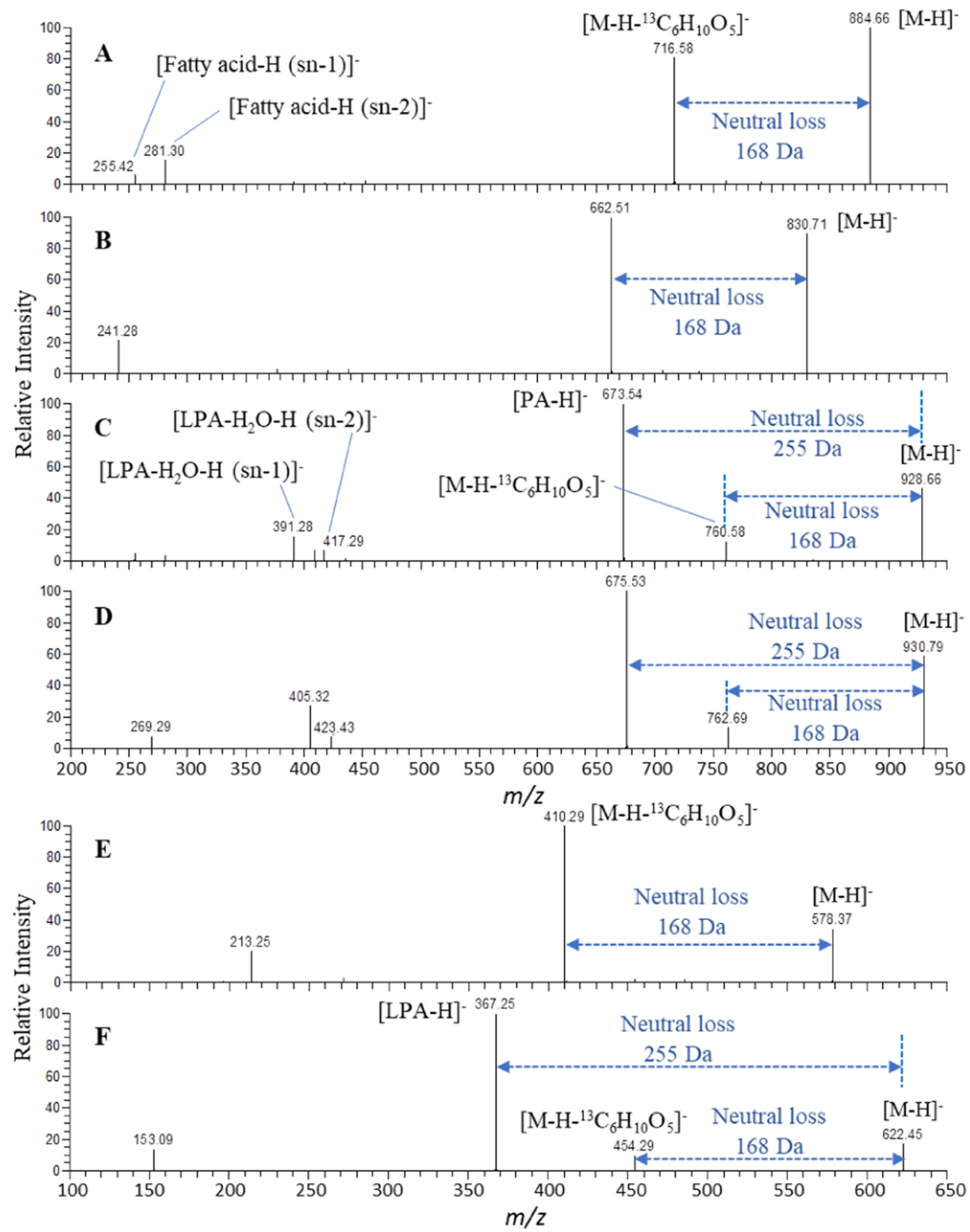

Figure 7. MS/MS spectra of molecular ion peaks of (A) $\left[{ }^{13} \mathrm{C}_{6}\right]$ Amadori-PE (16:0/18:1(9Z)), (B) $\left[{ }^{13} \mathrm{C}_{6}\right] \mathrm{Amadori}-\mathrm{PE}(15: 0 / 15: 0)$, (C) $\left[{ }^{13} \mathrm{C}_{6}\right]$ Amadori-PS $\left(16: 0 / 18: 1(9 \mathrm{Z})\right.$ ), and (D) $\left[{ }^{13} \mathrm{C}_{6}\right]$ Amadori-PS(17:0/17:0), (E) $\left[{ }^{13} \mathrm{C}_{6}\right]$ Amadori-LysoPE $(13: 0 / 0: 0)$, and (F) [ $\left.{ }^{13} \mathrm{C}_{6}\right]$ Amadori-LysoPS(13:0/0:0) in negative-ion mode.

-PS(16:0/18:1(9Z)), and -PS(17:0/17:0) were pure $(>95 \%)$, with purification process recoveries of about $43,51,31$, and $25 \%$, respectively. LC-UV chromatograms (Supporting Information Figure S1) also validated the high purity of $\left[{ }^{13} \mathrm{C}_{6}\right]$ Amadorilipids.

Compared to $\left[{ }^{13} \mathrm{C}_{6}\right]$ Amadori-PE/PS, $\left[{ }^{13} \mathrm{C}_{6}\right]$ Amadori-LysoPE/LysoPS are more hydrophilic. Thus, different strategies were employed for purification of $\left[{ }^{13} \mathrm{C}_{6}\right]$ Amadori-LysoPE/LysoPS. Instead of the Folch method, $\mathrm{C}_{18}$ SPE was performed to remove $\left[{ }^{13} \mathrm{C}_{6}\right] \mathrm{D}$-glucose for $\left[{ }^{13} \mathrm{C}_{6}\right]$ Amadori-LysoPE. In terms of $\left[{ }^{13} \mathrm{C}_{6}\right]$ Amadori-LysoPS, besides its low recovery on PBA SPE, we found it was more unstable than the other species. To make the purification more efficient for $\left[{ }^{13} \mathrm{C}_{6}\right]$ Amadori-LysoPS, direct purification using HPLC was employed, which utilizes isocratic elution with $75 \% \mathrm{MeOH}$ containing $5 \mathrm{mM} \mathrm{AF}$ and $0.1 \%$ phosphoric acid. After HPLC preparation, phosphoric acid in the eluent was removed by $\mathrm{C}_{18}$ SPE. $\left[{ }^{13} \mathrm{C}_{6}\right]$ Amadori-LysoPS was recovered in $\mathrm{MeOH}$, nitrogen-dried, and kept at $-80{ }^{\circ} \mathrm{C}$. LCMS full-scan chromatograms (Figure 5) showed that $\left[{ }^{13} \mathrm{C}_{6}\right]$ Amadori-LysoPE(13:0/0:0)/LysoPS(13:0/0:0) were pure $(>95 \%)$, with purification process recoveries of about 48 and $19 \%$, respectively. LC-UV chromatograms (Supporting Information Figure S2) also validated their high purity.

The mass accuracy of the six purified $\left[{ }^{13} \mathrm{C}_{6}\right]$ Amadori-lipids was confirmed by high-resolution mass spectrometry. A comparison between measured masses with calculated values exhibited a high mass accuracy (mass errors ranged from -2.6 to $2.4 \mathrm{ppm}$ ) (Supporting Information Table S1).

Isotopic purity of these six synthesized compounds was also investigated using high-mass-resolution LC-MS. Extracted ion chromatograms were generated and peak areas were integrated for each of the resolved isotopes related to these compounds 


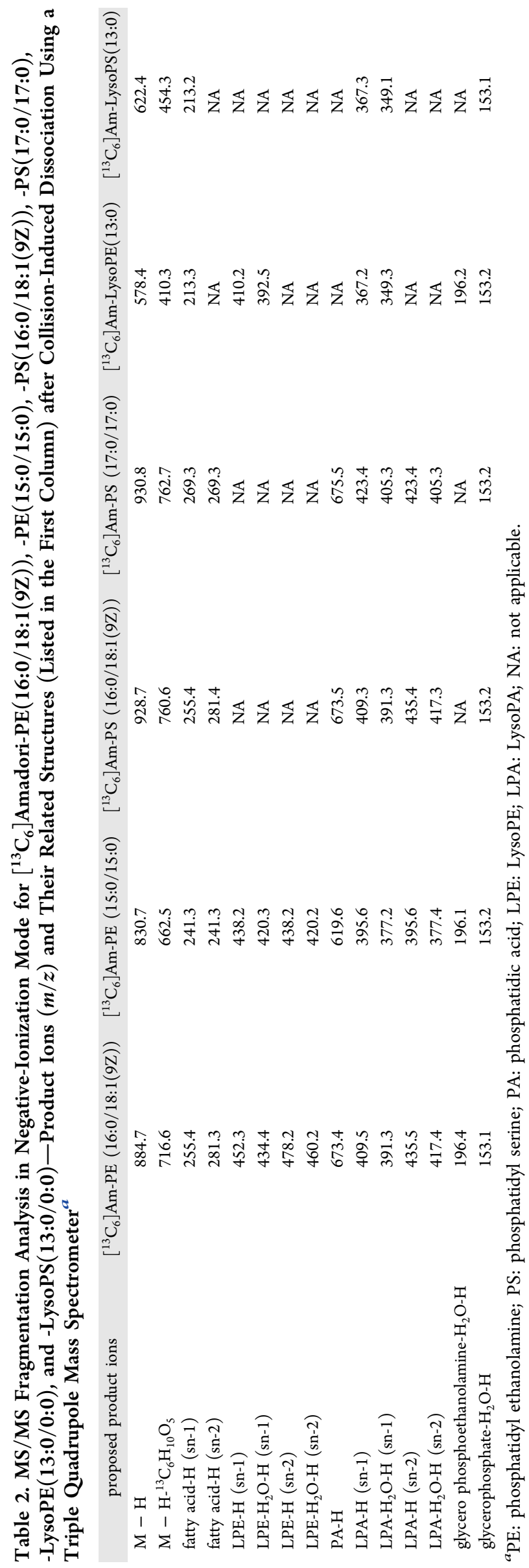

(Supporting Information Figure S3). After subtracting the contribution from the non-fully labeled natural isotopes, peak area values of isotopes were used to calculate the relative percent of isotopic enrichment and the overall isotopic purity. As a result, these six synthesized compounds were found to be 93.6794.3\% fully enriched (containing six labeled carbons); and the overall isotopic purities ranged from 98.9 to $99.0 \%$, showing that $98.9-99.0 \%$ of the potentially labeled positions in these compounds were occupied by ${ }^{13} \mathrm{C}$. This is in agreement with the $99 \%$ isotope purity of the starting material, $\left[{ }^{13} \mathrm{C}_{6}\right] \mathrm{D}$-glucose.

3.3. Characteristic MS/MS Fragmentations of $\left[{ }^{13} \mathrm{C}_{6}\right]-$ Amadori-Lipids. To further verify the authenticity of products synthesized, MS/MS fragmentation in both positive- and negative-ionization modes was performed on a triple quadrupole mass spectrometer under collision-induced dissociation. First, Q1 mass spectrum confirmed the most abundant molecular ion peaks as $[\mathrm{M}+\mathrm{H}]^{+}$ions in positive-ion mode and $[\mathrm{M}-\mathrm{H}]^{-}$ions in negative-ion mode (Supporting Information Figures S4 and S5). Next, product ion scanning was performed to investigate their fragmentation characteristics. In positiveion mode, neutral losses of $309.1 \mathrm{Da}\left(\mathrm{H}_{2} \mathrm{PO}_{4} \mathrm{C}_{2} \mathrm{H}_{4} \mathrm{NH}^{13} \mathrm{C}_{6} \mathrm{H}_{11} \mathrm{O}_{5}\right)$ and 353.1 Da $\left(\mathrm{H}_{2} \mathrm{PO}_{4} \mathrm{C}_{2} \mathrm{H}_{3} \mathrm{COOHNH}^{13} \mathrm{C}_{6} \mathrm{H}_{11} \mathrm{O}_{5}\right)$ from $[\mathrm{M}+$ $\mathrm{H}]^{+}$ion were observed for $\left[{ }^{13} \mathrm{C}_{6}\right]$ Amadori-PE/LysoPE and $\left[{ }^{13} \mathrm{C}_{6}\right]$ Amadori-PS/LysoPS, respectively, which were generated from the cleaved polar head groups (Figure 6). It was notable that a neutral loss of 168.1 Da (isotope-labeled Amadori moiety, ${ }^{13} \mathrm{C}_{6} \mathrm{H}_{10} \mathrm{O}_{5}$ ) - a characteristic neutral loss in MS/MS fragmentation of Amadori-peptides ${ }^{1,26}$ — could also be observed but with a much lower intensity (Figure 6, inset). Meanwhile, neutral losses of $\mathrm{H}_{2} \mathrm{O}, 2 \mathrm{H}_{2} \mathrm{O}, 3 \mathrm{H}_{2} \mathrm{O}$, and $3 \mathrm{H}_{2} \mathrm{O}+\mathrm{H}^{13} \mathrm{CHO}$ could also be observed for all six synthetic $\left[{ }^{13} \mathrm{C}_{6}\right]$ Amadori-lipids. In negativeion mode, fragment ions generated from the neutral loss of 168.1 Da became dominant for $\left[{ }^{13} \mathrm{C}_{6}\right]$ Amadori-PE/LysoPE species (Figure 7A,B,E), and could be clearly observed (10$12 \%$ relative intensities) for $\left[{ }^{13} \mathrm{C}_{6}\right]$ Amadori-PS/LysoPS (Figure $7 \mathrm{C}, \mathrm{D}, \mathrm{F}$ ). The base peaks in the MS/MS negative spectra of $\left[{ }^{13} \mathrm{C}_{6}\right]$ Amadori-PS/LysoPS belong to fragment ions generated from the neutral loss of $255.1 \mathrm{Da}\left([\mathrm{PA} / \mathrm{LPA}-\mathrm{H}]^{-}\right)$. Furthermore, other characteristic ions related to fatty acyl chains of synthetic compounds and fragment ions of glycerophosphate groups could also be identified from the MS/MS negative spectra in Figure 7 . These characteristic ions are summarized in Table 2, which are consistent with the fragmentation patterns of phospholipids previously reported. ${ }^{27,28}$ Representative fragmentation schemes of these synthetic $\left[{ }^{13} \mathrm{C}_{6}\right]$ Amadori-phospholipids are shown in Figure 8, taking $\left[{ }^{13} \mathrm{C}_{6}\right]$ Amadori-PE(16:0/18:1(9Z)) and $\left[{ }^{13} \mathrm{C}_{6}\right]$ Amadori-PS(16:0/18:1(9Z)) as examples.

Unlabeled analogues corresponding to these six $\left[{ }^{13} \mathrm{C}_{6}\right]$ labeled compounds were also synthesized and subjected to LCMS/MS analysis. Each unlabeled analogue had the same retention time as its corresponding labeled compound under the same LC condition (Supporting Information, Figure S6). From their MS/MS spectra in positive-ion mode, expected neutral losses of $303.1 \mathrm{Da}\left(\mathrm{H}_{2} \mathrm{PO}_{4} \mathrm{C}_{2} \mathrm{H}_{4} \mathrm{NHC}_{6} \mathrm{H}_{11} \mathrm{O}_{5}\right)$ and $347.1 \mathrm{Da}$ $\left(\mathrm{H}_{2} \mathrm{PO}_{4} \mathrm{C}_{2} \mathrm{H}_{3} \mathrm{COOHNHC} \mathrm{H}_{11} \mathrm{O}_{5}\right)$ from $[\mathrm{M}+\mathrm{H}]^{+}$ion could be observed for Amadori-PE/LysoPE and Amadori-PS/ LysoPS, respectively (Supporting Information Figure S7). From their MS/MS spectra in negative-ion mode, the expected neutral loss of 162.1 Da (Amadori moiety) could also be observed for all of these six unlabeled compounds (Supporting Information Figure S8). Collectively, the expected fragmentation patterns and the corresponding mass shifts observed for all synthetic 


\section{(A) $\left[{ }^{13} \mathrm{C}_{6}\right]$ Amadori-PE(16:0/18:1(9Z)) in positive ion mode}

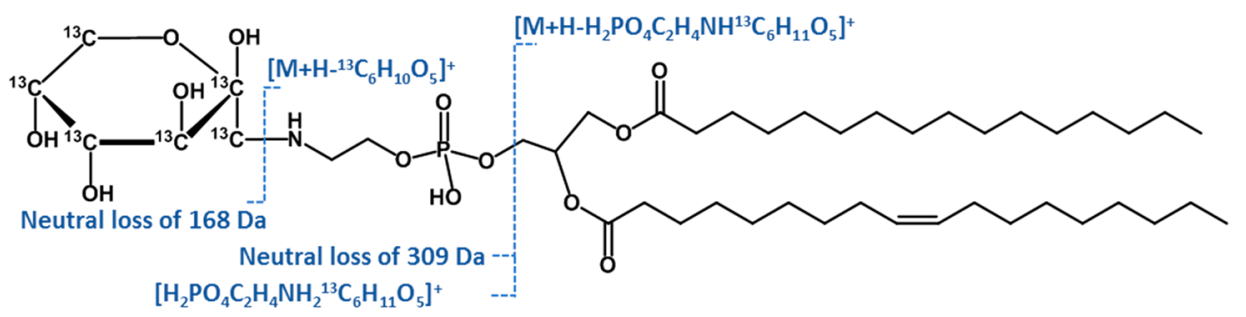

(B) $\left[{ }^{13} C_{6}\right]$ Amadori-PE(16:0/18:1(9Z)) in negative ion mode

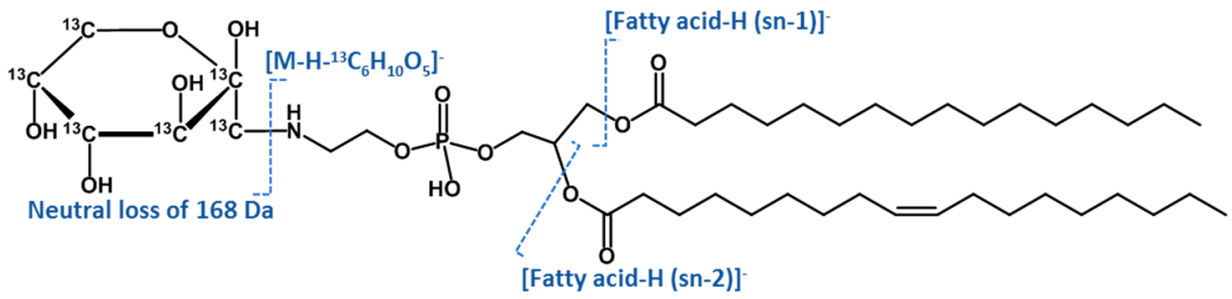

(C) $\left[{ }^{13} \mathrm{C}_{6}\right]$ Amadori-PS(16:0/18:1(9Z)) in negative ion mode

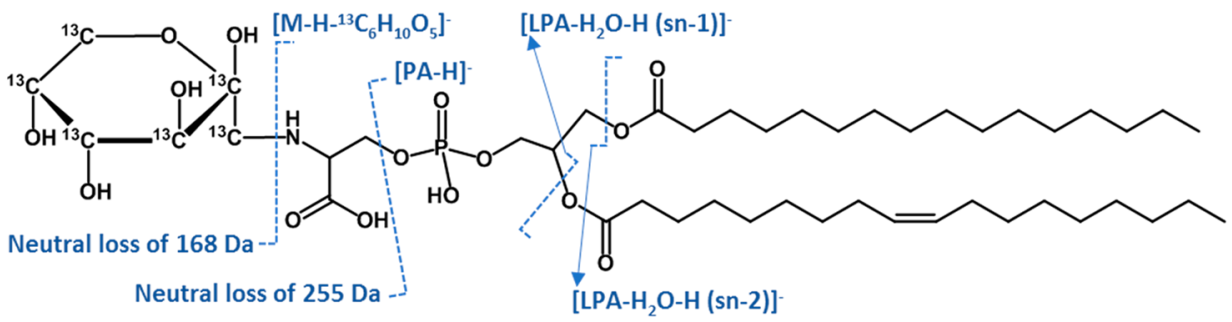

Figure 8. MS/MS fragmentation schemes of (A) $\left[{ }^{13} \mathrm{C}_{6}\right]$ Amadori-PE(16:0/18:1(9Z)) in positive-ion mode and (B) negative-ion mode, and (C) $\left[{ }^{13} \mathrm{C}_{6}\right]$ Amadori-PS(16:0/18:1(9Z)) in negative-ion mode. The MS/MS spectra corresponding to (A), (B), and (C) are shown in Figures 6A and $7 \mathrm{~A}, \mathrm{C}$.

$\left[{ }^{13} \mathrm{C}_{6}\right]$ Amadori-lipids unambiguously validated the identification of these novel compounds.

\section{CONCLUSIONS}

In this study, six stable isotope-labeled $\left[{ }^{13} \mathrm{C}_{6}\right]$ Amadori-glycated lipids were synthesized, purified, and structurally confirmed using accurate mass measurement and tandem mass spectrometry, covering four types of lipids, including Amadori-PE, -PS, -LysoPE, and -LysoPS. Optimal conditions for the synthesis and purification of these four types of stable isotope-labeled Amadori-glycated lipids were obtained. MS/MS fragmentation in both positive- and negative-ion modes validated the identification of these novel synthetic compounds. The high purity (>95\%) of these synthetic compounds was verified by both LC-MS full-scan analysis and LC-UV analysis. As a result, successful preparation of highly purified stable isotope-labeled Amadori-lipid standards makes it possible to develop targeted LC-MS/MS methods for accurate analysis of endogenous Amadori-glycated phospholipids from biological samples.

\section{ASSOCIATED CONTENT}

\section{S Supporting Information}

The Supporting Information is available free of charge on the ACS Publications website at DOI: 10.1021/acsomega.8b01893.

HPLC-UV chromatograms, full-scan MS, and MS/MS spectra of synthesized labeled and unlabeled AmadoriPE, -PS, -LysoPE, and -LysoPS compounds (PDF)

\section{AUTHOR INFORMATION}

\section{Corresponding Author}

*E-mail: q_zhang2@uncg.edu.

ORCID $\odot$

Qibin Zhang: 0000-0002-6135-8706

Notes

The authors declare no competing financial interest.

\section{ACKNOWLEDGMENTS}

The authors gratefully acknowledge funding from the National Institute of Diabetes and Digestive and Kidney Diseases of the National Institutes of Health (R01 DK116731) and the American Heart Association (17CSA33570025) for support of this research.

\section{REFERENCES}

(1) Zhang, Q.; Ames, J. M.; Smith, R. D.; Baynes, J. W.; Metz, T. O. A perspective on the Maillard reaction and the analysis of protein glycation by mass spectrometry: probing the pathogenesis of chronic disease. J. proteome Res. 2009, 8, 754-769.

(2) Ledl, F.; Schleicher, E. New Aspects of the Maillard Reaction in Foods and in the Human Body. Angew. Chem., Int. Ed. 1990, 29, 565594

(3) Miyazawa, T.; Nakagawa, K.; Shimasaki, S.; Nagai, R. Lipid glycation and protein glycation in diabetes and atherosclerosis. Amino Acids 2012, 42, 1163-1170. 
(4) Bucala, R. Lipid and lipoprotein modification by advanced glycosylation end-products: role in atherosclerosis. Exp. Physiol. 1997, 82, 327-337.

(5) Bucala, R.; Makita, Z.; Koschinsky, T.; Cerami, A.; Vlassara, H. Lipid advanced glycosylation: pathway for lipid oxidation in vivo. Proc. Natl. Acad. Sci. U.S.A. 1993, 90, 6434-6438.

(6) Bucala, R.; Makita, Z.; Vega, G.; Grundy, S.; Koschinsky, T.; Cerami, A.; Vlassara, H. Modification of low density lipoprotein by advanced glycation end products contributes to the dyslipidemia of diabetes and renal insufficiency. Proc. Natl. Acad. Sci. U.S.A. 1994, 91, 9441-9445.

(7) Nagashima, T.; Oikawa, S.; Hirayama, Y.; Tokita, Y.; Sekikawa, A.; Ishigaki, Y.; Yamada, R.; Miyazawa, T. Increase of serum phosphatidylcholine hydroperoxide dependent on glycemic control in type 2 diabetic patients. Diabetes Res. Clin. Pract. 2002, 56, 19-25.

(8) Kinoshita, M.; Oikawa, S.; Hayasaka, K.; Sekikawa, A.; Nagashima, T.; Toyota, T.; Miyazawa, T. Age-related increases in plasma phosphatidylcholine hydroperoxide concentrations in control subjects and patients with hyperlipidemia. Clin. Chem. 2000, 46, 822828.

(9) Sell, D. R.; Lane, M. A.; Johnson, W. A.; Masoro, E. J.; Mock, O. B.; Reiser, K. M.; Fogarty, J. F.; Cutler, R. G.; Ingram, D. K.; Roth, G. S.; Monnier, V. M. Longevity and the genetic determination of collagen glycoxidation kinetics in mammalian senescence. Proc. Natl. Acad. Sci. U.S.A. 1996, 93, 485-490.

(10) Sookwong, P.; Nakagawa, K.; Fujita, I.; Shoji, N.; Miyazawa, T. Amadori-glycated phosphatidylethanolamine, a potential marker for hyperglycemia, in streptozotocin-induced diabetic rats. Lipids 2011, 46, 943-952.

(11) Oak, J.; Nakagawa, K.; Miyazawa, T. Synthetically prepared Aamadori-glycated phosphatidylethanolaminecan trigger lipid peroxidation via free radical reactions. FEBS Lett. 2000, 481, 26-30.

(12) Utzmann, C. M.; Lederer, M. O. Identification and quantification of aminophospholipid-linked Maillard compounds in model systems and egg yolk products. J. Agric. Food Chem. 2000, 48, $1000-1008$.

(13) Nakagawa, K.; Oak, J. H.; Higuchi, O.; Tsuzuki, T.; Oikawa, S.; Otani, H.; Mune, M.; Cai, H.; Miyazawa, T. Ion-trap tandem mass spectrometric analysis of Amadori-glycated phosphatidylethanolamine in human plasma with or without diabetes. J. Lipid Res. 2005, 46, 2514-2524.

(14) Kodate, A.; Otoki, Y.; Shimizu, N.; Ito, J.; Kato, S.; Umetsu, N.; Miyazawa, T.; Nakagawa, K. Development of quantitation method for glycated aminophospholipids at the molecular species level in powdered milk and powdered buttermilk. Sci. Rep. 2018, 8, No. 8729.

(15) Xenakis, D.; et al. Organic synthesis of Amadori rearrangement products. Synthesis 1983, 541-543.

(16) Utzmann, C. M.; Lederer, M. O. Independent synthesis of aminophospholipid-linked maillard products. Carbohydr. Res. 2000, 325, 157-168.

(17) Lertsiri, S.; Shiraishi, M.; Miyazawa, T. Identification of deoxyD-fructosyl phosphatidylethanolamine as a non-enzymic glycation product of phosphatidylethanolamine and its occurrence in human blood plasma and red blood cells. Biosci., Biotechnol., Biochem. 1998, 62, 893-901.

(18) Miyazawa, T.; Oak, J. H.; Nakagawa, K. A convenient method for preparation of high-purity, Amadori-glycated phosphatidylethanolamine and its prooxidant effect. Ann. N. Y. Acad. Sci. 2005, 1043, 276-279.

(19) Miyazawa, T.; Kamiyoshihara, R.; Shimizu, N.; Harigae, T.; Otoki, Y.; Ito, J.; Kato, S.; Miyazawa, T.; Nakagawa, K. Amadoriglycated phosphatidylethanolamine enhances the physical stability and selective targeting ability of liposomes. R. Soc. Open Sci. 2018, 5, No. 171249.

(20) Narváez-Rivas, M.; Zhang, Q. Comprehensive untargeted lipidomic analysis using core-shell C30 particle column and high field orbitrap mass spectrometer. J. Chromatogr. A 2016, 1440, 123-134.

(21) Lambert, C. R.; Truscott, T. G.; Black, H. S. Reactivity of butylated hydroxytoluene. Free Radical Biol. Med. 1996, 21, 395-400.
(22) Yehye, W. A.; Rahman, N. A.; Ariffin, A.; Abd Hamid, S. B.; Alhadi, A. A.; Kadir, F. A.; Yaeghoobi, M. Understanding the chemistry behind the antioxidant activities of butylated hydroxytoluene (BHT): a review. Eur. J. Med. Chem. 2015, 101, 295-312.

(23) Peters, J. A. Interactions between boric acid derivatives and saccharides in aqueous media: Structures and stabilities of resulting esters. Coord. Chem. Rev. 2014, 268, 1-22.

(24) Springsteen, G.; Wang, B. A detailed examination of boronic acid-diol complexation. Tetrahedron 2002, 58, 5291-5300.

(25) Zhang, Q.; Tang, N.; Brock, J. W.; Mottaz, H. M.; Ames, J. M.; Baynes, J. W.; Smith, R. D.; Metz, T. O. Enrichment and analysis of nonenzymatically glycated peptides: boronate affinity chromatography coupled with electron-transfer dissociation mass spectrometry. $J$. proteome Res. 2007, 6, 2323-2330.

(26) Zhang, Q.; Petyuk, V. A.; Schepmoes, A. A.; Orton, D. J.; Monroe, M. E.; Yang, F.; Smith, R. D.; Metz, T. O. Analysis of nonenzymatically glycated peptides: neutral-loss-triggered MS(3) versus multi-stage activation tandem mass spectrometry. Rapid Commun. Mass Spectrom. 2008, 22, 3027-3034.

(27) Larsen, A.; Jacobsen, P. B.; Skotland, T.; Uran, S. Collisioninduced dissociation of glycero phospholipids using electrospray iontrap mass spectometry. Rapid Commun. Mass Spectrom. 2001, 15, 2393-2398.

(28) Pi, J.; Wu, X.; Feng, Y. Fragmentation patterns of five types of phospholipids by ultra-high-performance liquid chromatography electrospray ionization quadrupole time-of-flight tandem mass spectrometry. Anal. Methods 2016, 8, 1319-1332. 